Research Article

\title{
Immune Exclusion Is Frequent in Small-Cell Carcinoma of the Bladder
}

\author{
Tim Mandelkow, ${ }^{1}$ Niclas C. Blessin, ${ }^{1}$ Eva Lueerss, ${ }^{1}$ Laura Pott, ${ }^{1}$ Ronald Simon $\left(\mathbb{D},{ }^{1}\right.$ \\ Wenchao Li, ${ }^{1}$ Björn Wellge, ${ }^{2}$ Nicolaus F. Debatin, ${ }^{1}$ Doris Höflmayer, ${ }^{1}$ Jakob R. Izbicki, ${ }^{2}$ \\ Franziska Büischeck, ${ }^{1}$ Andreas M. Luebke, ${ }^{1}$ Corinna Wittmer, ${ }^{1}$ Frank Jacobsen, ${ }^{1}$ \\ Florian Lutz, ${ }^{1}$ Eike Burandt, ${ }^{1}$ Stefan Steurer ${ }^{D},{ }^{1}$ Guido Sauter, ${ }^{1}$ Maria Christina Tsourlakis, ${ }^{1}$ \\ Waldemar Wilczak, ${ }^{1}$ Andrea Hinsch, ${ }^{1}$ and Sarah Minner ${ }^{1}$ \\ ${ }^{1}$ Department of Pathology, University Medical Center Hamburg-Eppendorf, Germany \\ ${ }^{2}$ Department of General, Visceral and Thoracic Surgery, University Medical Center Hamburg-Eppendorf, Germany
}

Correspondence should be addressed to Ronald Simon; r.simon@uke.de

Received 6 February 2019; Accepted 7 March 2019; Published 2 May 2019

Academic Editor: Chiara Nicolazzo

Copyright (c) 2019 Tim Mandelkow et al. This is an open access article distributed under the Creative Commons Attribution License, which permits unrestricted use, distribution, and reproduction in any medium, provided the original work is properly cited.

\begin{abstract}
Small-cell cancer of the urinary bladder is a rare but highly aggressive disease. It is currently unclear whether immune checkpoint therapies that have been approved for urothelial carcinomas will also be efficient in small-cell carcinomas. In this study, we analyzed potential predictors of response including PD-L1 expression and the quantity and location of tumor-infiltrating lymphocytes (TILs) in 12 small-cell and 69 "classical" urothelial cancers by immunohistochemistry. The analysis revealed that small-cell carcinomas were characterized by the virtual absence of PD-L1 expression and an "immune-excluded" phenotype with only a few TILs in the center of the tumor (CT). In small-cell carcinomas, the average immune cell density in the CT (CD3: 159 \pm 206 , CD8: $87 \pm 169$ cells $/ \mathrm{mm}^{2}$ ) was more than 3 times lower than that in the urothelial carcinomas (CD3: $625 \pm 800, p<0.001$; CD8: $362 \pm 626$ cells $/ \mathrm{mm}^{2}, p=0.004$ ) while there was no significant difference in the immune cell density at the invasive margin (IM) (small-cell carcinomas CD3: $899 \pm 733$, CD8: $404 \pm 433$ cells $/ \mathrm{mm}^{2}$; urothelial carcinomas CD3: $1167 \pm 1206, p=0.31$; CD8: 582 \pm 864 cells $\left./ \mathrm{mm}^{2}, p=0.27\right)$. Positive PD-L1 staining was found in $39 \%$ of urothelial cancers, but in only $8 \%$ of small-cell bladder cancer cases $(p=0.04)$. Concordant with these data, a sharp decrease of PD-L1 positivity from $>80 \%$ to $0 \%$ positive cells and of TILS in the CT from 466-1063 CD3-positive cells $/ \mathrm{mm}^{2}$ to $50-109$ CD3-positive cells $/ \mathrm{mm}^{2}$ was observed in two cancers with clear-cut progression from "classical" urothelial to small-cell carcinoma. In conclusion, these data demonstrate that small-cell bladder cancer commonly exhibits an immune-excluded phenotype.
\end{abstract}

\section{Introduction}

Small-cell cancer of the urinary bladder represents a rare bladder cancer subtype accounting for about one percent of urinary bladder cancers $[1,2]$. They are characterized by early metastasis and a particularly poor prognosis [2]. Treatment usually includes one of chemotherapy, radiotherapy, or cystectomy, although there is no accepted standard treatment for this cancer type [2]. Despite therapy, about $80 \%$ of patients die within 5 years after diagnosis $[1,3]$.

Immune checkpoint inhibitors represent a new and promising therapeutic option for a variety of cancer types, including urinary bladder cancer. Several immune checkpoint inhibitors have recently been approved by the FDA for therapy of refractory or metastatic urothelial tumors [4]. The successful treatment of a patient with metastatic small- 
cell bladder carcinoma with pembrolizumab [5], a programmed cell death protein 1 (PD-1) inhibitor, has led to an ongoing phase II study (NCT03430895) to evaluate anticheckpoint therapies in patients with rare bladder cancer entities including small-cell carcinoma.

Expression of programmed cell death-ligand 1 (PD-L1) in tumor cells and cancer-associated inflammatory cells is one of the best established predictive parameters for response to current anticheckpoint therapies in cancer [6, 7]. A growing number of reports show that the quantity and location of leucocytes, particularly $\mathrm{CD}^{+} \mathrm{T}$ lymphocytes, relative to the cancer cells may also be relevant to understand the interaction of the immune system with a cancer [8-10]. The most commonly used classifications to describe patterns of immune cell infiltration include the "inflamed" (tumor rich in tumor-infiltrating lymphocytes), the "immune-excluded" (presence of immune cells at the invasive margin but absence of immune cells in the center of the tumor), and the "immune-desert" phenotype (absence of relevant numbers of immune cells both at the periphery and in the center of the tumor) $[11,12]$.

To understand the spatial composition and distribution of immune cells in small-cell bladder carcinoma, we investigated the PD-L1 status and the T cell infiltration patterns in 12 small-cell bladder carcinomas and compared these findings with data from 69 "classical" urothelial carcinomas.

\section{Material and Methods}

2.1. Patients and Tissues. Formalin-fixed paraffin-embedded tumor tissue samples from 12 patients with small-cell bladder carcinomas and 69 patients with urothelial carcinomas of the bladder were retrieved from the archives of the Institute of Pathology of the University Medical Center HamburgEppendorf. The usage of archived diagnostic leftover tissues and clinical data from anonymized patients and their analysis for research purposes has been approved by local laws (HmbKHG, \$12a).

2.2. Immunohistochemistry. Freshly cut consecutive conventional large tissue sections were stained for CD3, CD8, PD1, and PD-L1 at the same day. Slides were deparaffinized and exposed to heat-induced antigen retrieval for 5 minutes in an autoclave at $121^{\circ} \mathrm{C}$ in $\mathrm{pH} 6$ antigen retrieval buffer (Leica Biosystems, Wetzlar, Germany; \#AR9961) for PD-1 and pH 9 retrieval buffer (Leica Biosystems, Wetzlar, Germany; \# AR9640) for CD3, CD8, and PD-L1. Primary antibody specific for CD3 (rabbit polyclonal antibody, Dako, Santa Clara, US; \#IR503; undiluted), CD8 (mouse monoclonal antibody, Dako, Santa Clara, US; \#IR623; undiluted), PD-1 (mouse monoclonal [NAT105] antibody, Abcam, Cambridge, UK; \#ab52587; $1: 50$ ), and PD-L1 (rabbit monoclonal $\left[\right.$ E1L3N $\left.{ }^{\circledR}\right]$ antibody, Cell Signaling, Danvers, Massachusetts; \#13684; $1: 200)$ was applied at $37^{\circ} \mathrm{C}$ for 60 minutes. Bound antibody was then visualized using the EnVision Kit (Dako, Glostrup, Denmark) according to the manufacturer's directions.
2.3. Definition of Compartments and Quantification of CD3, CD8, and PD-1 Immunostaining. Digital images of stained slides were acquired using Leica's Aperio VERSA 8 automated microscope. The invasive margin (IM) and the center of the tumor (CT) were defined in each digital image. IM was defined as the area expanding $300 \mu \mathrm{m}$ into the stroma and $50 \mu \mathrm{m}$ into the tumor measured from the stromal tumor borderline. CT was defined as an area remote from the stromal tumor borderline in the depth of the tumor bulk. All areas matching these criteria were included in the analysis of each slide, except from areas with obvious staining artefacts or damaged tissue that were excluded from further analysis. Image analysis of the IM and CT areas was performed using ImageScope software package (Leica Microsystems, Wetzlar, Germany). The number of stained cells and the size of the measured region were recorded in each area of IM and CT, and the density of stained cells (number of cells per square $\mathrm{mm}$ ) was calculated from these data.

2.4. Analysis of PD-L1 Immunostaining. For each cancer, the percentage of PD-L1-positive cancer and inflammatory cells was recorded. Tumors showing detectable PD-L1 staining in $\geq 1 \%$ of tumor cells were considered positive [13].

2.5. Statistics. JMP Pro 12 software package (SAS Institute Inc., NC, USA) and R version 3.4.3 (The R Foundation) [14] were used to plot the data, to calculate chi-square $p$ values, to perform analysis of variance (ANOVA), and to calculate Pearson's correlation coefficient $(\rho)$ in order to explore differences of cell densities between the IM and the CT.

\section{Results}

3.1. T Cell Density in Small-Cell Bladder and Urothelial Carcinomas. All 12 small-cell carcinomas and 69 urothelial carcinomas contained lymphocytes positive for CD3, CD8, and PD-1 at the invasive margin (IM) and in the center of the tumor (CT). Representative images with different densities of $\mathrm{CD}^{+} \mathrm{T}$ cells at the IM and in the CT are shown in Figure 1.

In small-cell carcinomas, the density of $\mathrm{T}$ cells was variable between patients but always markedly lower in CT than at IM $(p<0.05$ each). This held true for CD3-positive cells $/ \mathrm{mm}^{2}$ (IM: $899 \pm 733, \mathrm{CT}: 159 \pm 206$ ), CD8-positive cells $/ \mathrm{mm}^{2}$ (IM: $404 \pm 433$, CT: $87 \pm 169$ ), and for PD-1positive cells $/ \mathrm{mm}^{2}$ (IM: $667 \pm 595$, CT: $\left.215 \pm 115\right)$. These differences were less evident in urothelial carcinomas. This was true for all $\mathrm{T}$ cell types including CD3-positive cells $/ \mathrm{mm}^{2}$ (IM: $1167 \pm 1206$, CT: $625 \pm 800$ ), CD8-positive cells $/ \mathrm{mm}^{2}$ (IM: $582 \pm 864$, CT: $362 \pm 626$ ), and PD-1-positive cells $/ \mathrm{mm}^{2}$ (IM: $334 \pm 517$, CT: $208 \pm 349$ ). Further comparisons revealed that the $\mathrm{T}$ cell density in the $\mathrm{CT}$ of small-cell cancers was significantly lower than that of urothelial cancers (CD3: $p<0.001$, CD8: $p=0.004)$, while there were no significant differences at the IM (CD3: $p=0.31, \mathrm{CD} 8: p=0.27)$. All data are shown in Figure 2 and Supplementary Figure 1.

3.2. PD-L1 Status in Small-Cell and Urothelial Bladder Cancer. Two cases were excluded from this analysis because 


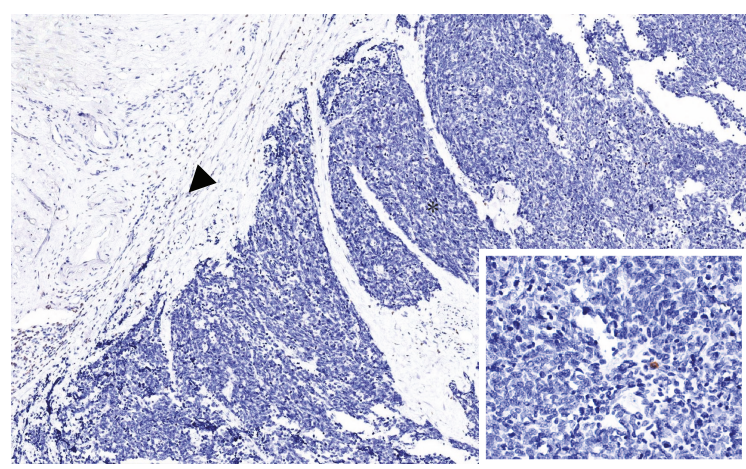

(a)

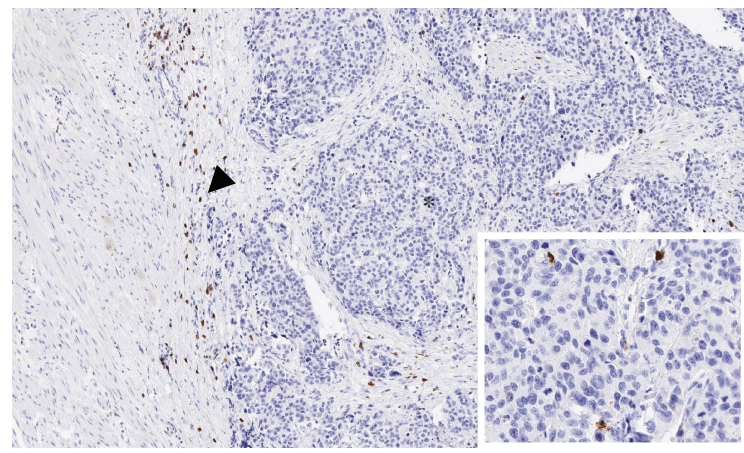

(c)

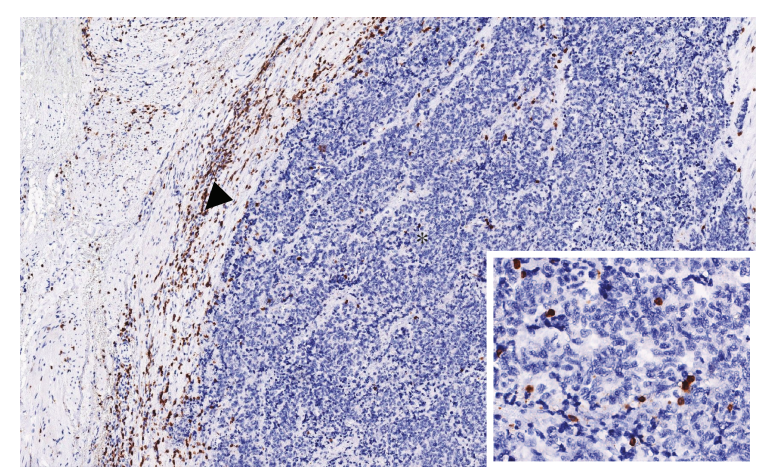

(b)

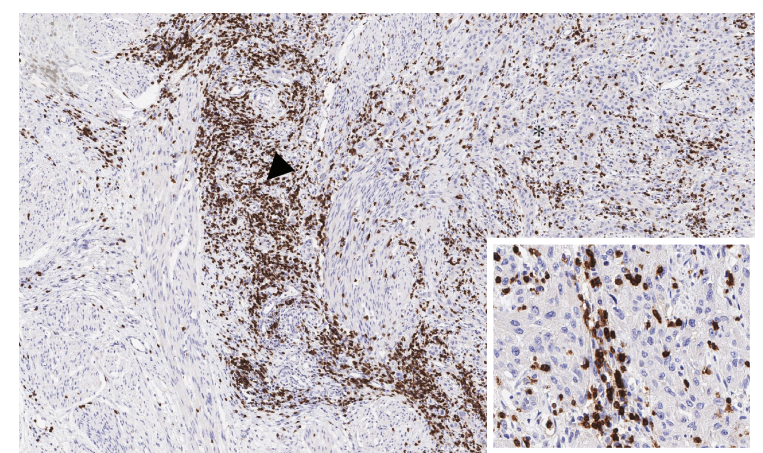

(d)

FIGURE 1: Representative pictures of CD3 staining (brown color) in (a, b) two cases of small-cell and (c, d) two cases of urothelial carcinoma of the bladder. Panels $(a, c)$ show examples of the immune-desert phenotype and $(b, d)$ examples of the immune-excluded phenotype. Arrowheads indicate the invasive margin. Asterisks label the center of the tumor, shown also in the insets at 400x magnification.

PD-L1 staining was not unequivocally interpretable. PD-L1 staining was less frequent and less intense in small-cell cancer than that in urothelial bladder cancer. Positive PD-L1 staining was found in the tumor cells of 26/67 (39\%) urothelial carcinomas but in only $1 / 12(8 \%, p=0.04)$ of small-cell carcinomas. The one PD-L1-positive small-cell bladder cancer had 10\% PD-L1-positive tumor cells. This was markedly less than the average fraction of PD-L1-positive tumor cells seen in $26 \mathrm{PD}$-L1-positive urothelial carcinomas $(42 \% \pm 36 \%)$.

\subsection{Mixed Tumors with Small-Cell and Urothelial Cancer} Components. Our cohort included two cases that contained adjacent areas of small-cell and urothelial carcinoma (Figure 3). Both cases showed a dramatically lower $\mathrm{T}$ cell density in the CT of SCCB than that in the CT of UCB irrespective of the analyzed markers (CD3, CD8, and PD-1; Table 1). Again, no differences were found for the $\mathrm{T}$ cell densities in the IMs of both bladder cancer proportions. In addition, both cases showed strong PD-L1 staining in $80 \%$ and $90 \%$ of cells in the urothelial cancer component while PDL1 staining was fully absent in the small-cell cancer fraction (Figure 3).

\section{Discussion}

The data from this study identify "immune exclusion" as the dominant immune pattern of small-cell carcinoma of the urinary bladder.
The typical features of immune exclusion were present in all 12 small-cell carcinomas of the urinary bladder, including an at least fivefold lower number of T cells in the CT as compared to the IM. This was in contrast to urothelial carcinomas, where the findings were more variable but dominated by characteristics of the "inflamed" cancer phenotype. Comparable absolute numbers on T cell density in "cells per $\mathrm{mm}^{2 \text { " }}$ are not available in the literature, but the inflamed phenotype had been attributed to urothelial bladder cancer before [15]. So far, immune exclusion has been mostly reported from colorectal and pancreatic adenocarcinomas [15]. It was also found in a large fraction of small-cell lung cancers (SCLC) [15-17]. That small-cell carcinoma of the urinary bladder is also characterized by immune exclusion which provides another argument for a considerable similarity between small-cell carcinomas of the lung and the bladder which had been earlier suggested by comparative studies analyzing genomic alterations [18, 19].

Tumors containing distinct areas of both the "inflamed" and the "immune-excluded" phenotype may serve as models to study the molecular mechanisms underlying immune exclusion. About $40 \%$ of small-cell carcinomas of the bladder show mixed tumor components of small-cell and urothelial cancers [1]. The close spatial relationship with unequivocal transition of both histological subtypes indicates that smallcell cancers typically develop from urothelial carcinomas. Studies using comparative genomic hybridization, nextgeneration sequencing, and immunohistochemistry have 

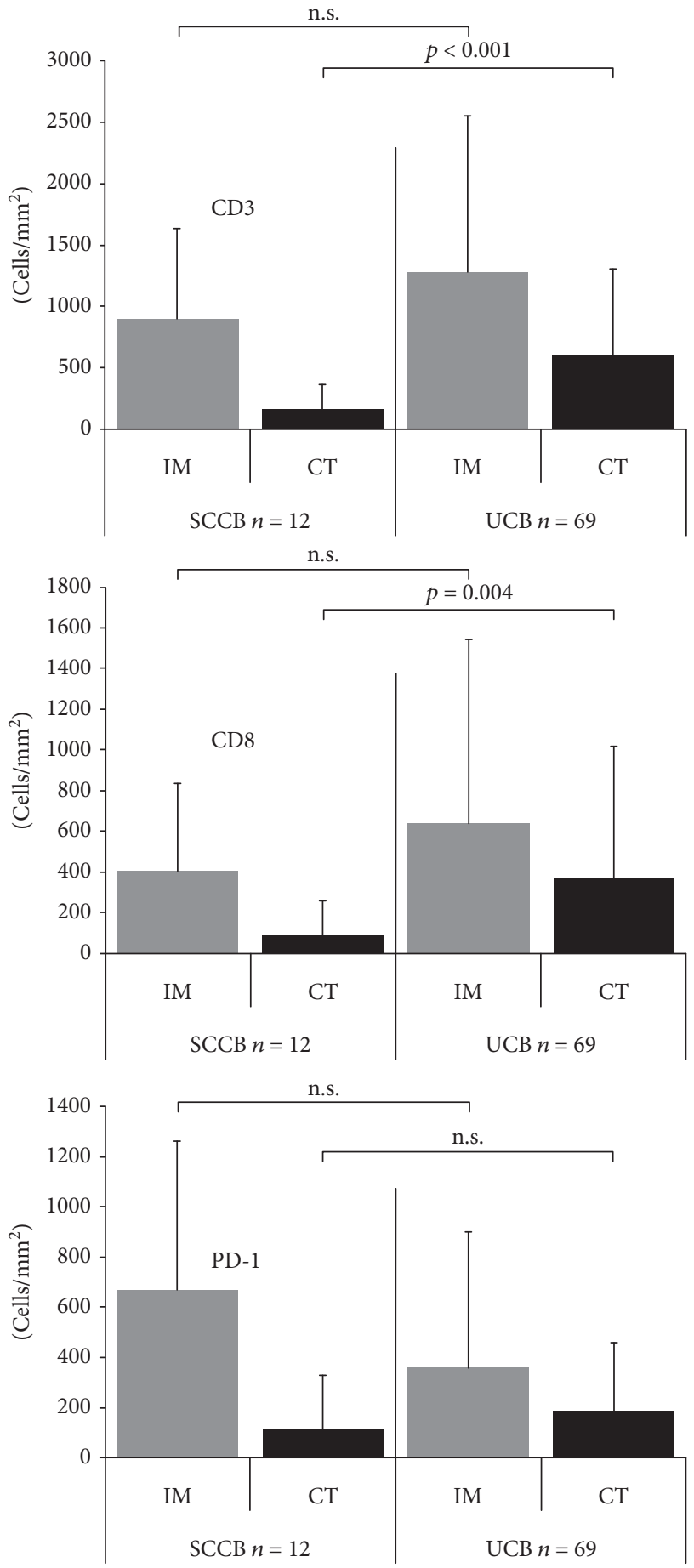

Figure 2: Comparison of CD3-, CD8-, and PD-1-positive cell densities at the invasive margin (IM) and center of the tumor (CT) between 12 small-cell carcinomas (SCCB) and 69 urothelial carcinomas of the bladder (UCB).

demonstrated that urothelial carcinoma progresses to smallcell cancer through accumulation of additional genomic alterations. These include both gross chromosomal changes such as deletions (1q31-qter, 2q14-qter, 3q, and 10q) and gains (1q21-q23,10p) [18] as well as somatic mutations of the RB1 tumor suppressor and TERT promotor [19-21].
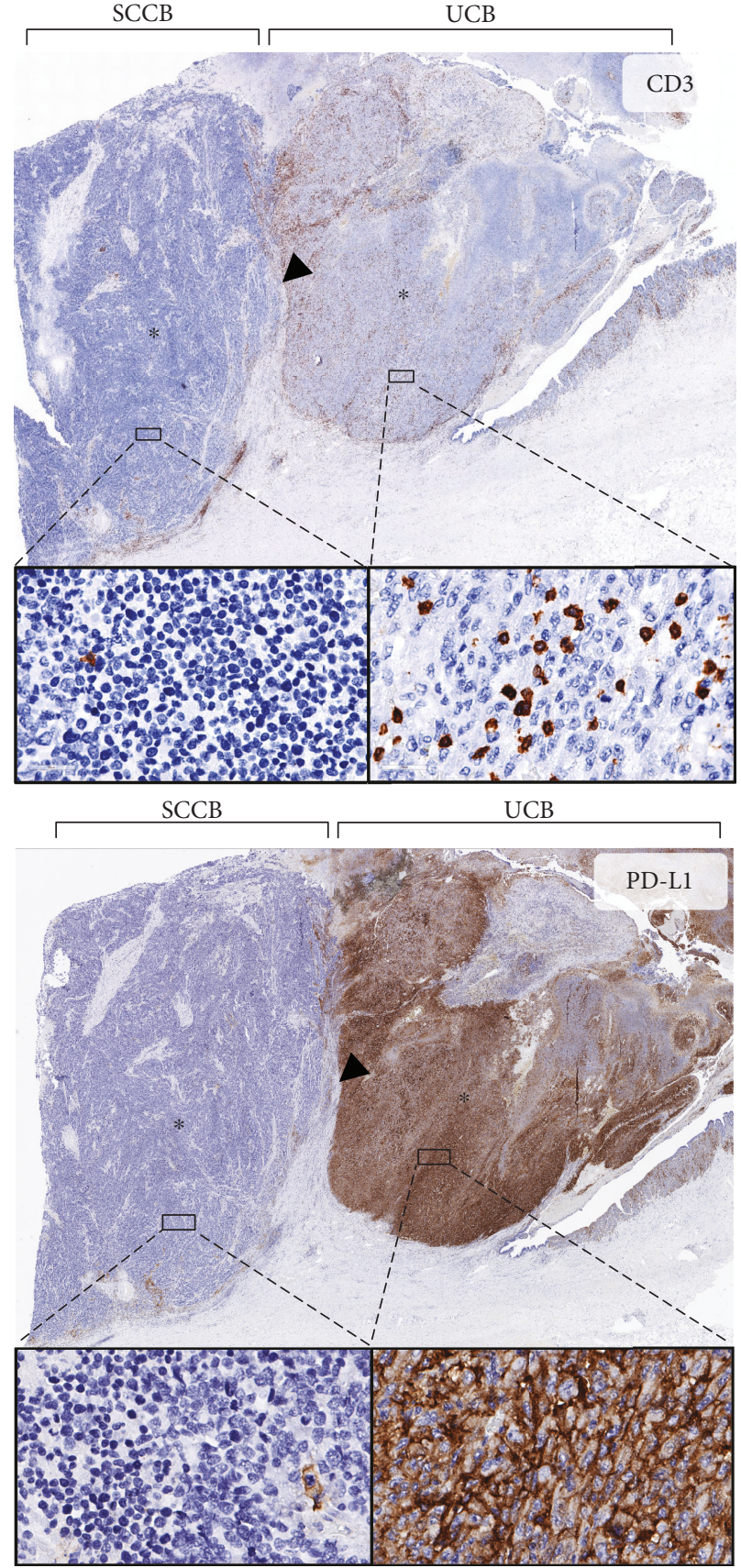

FIGURE 3: CD3 and PD-L1 staining of a sample from patient 4 that contained adjacent areas of small-cell and urothelial carcinoma of the bladder. Note the invasive margin (arrowhead) and the center of the tumor (asterisks). Insets show 400x magnification of the tumor bulk.

Our cohort contained two cases with presumable urothelial to small-cell cancer progression, and both cancers showed remarkably similar features. Both had high PD-L1 expression and high numbers of $\mathrm{CD}^{+}$lymphocytes at IM and in CT of the urothelial cancer component and a complete loss of PDL1 expression and an almost complete loss of CT CD8 ${ }^{+}$lymphocytes in the small-cell cancer component. Those both cancers completely lost their strong and abundant PD-L1 expression which demonstrates how variable the PD-L1 
TABle 1: Total T cell, cytotoxic T cell, and PD-1-positive T cell densities at the invasive margin (IM) and the center of the tumor (CT) in two patients with adjacent areas of small-cell and urothelial cell bladder cancer.

\begin{tabular}{|c|c|c|c|c|c|c|}
\hline Patient & $\mathrm{CD}^{+}\left(\right.$cells $\left./ \mathrm{mm}^{2}\right)$ & $\begin{array}{c}\text { Small-cell part } \\
\mathrm{CD}^{+}\left(\text {cells } / \mathrm{mm}^{2}\right)\end{array}$ & $\mathrm{PD}-1^{+}\left(\right.$cells $\left./ \mathrm{mm}^{2}\right)$ & $\mathrm{CD}^{+}\left(\right.$cells $\left./ \mathrm{mm}^{2}\right)$ & $\begin{array}{c}\text { Urothelial part } \\
\mathrm{CD}^{+}\left(\text {cells } / \mathrm{mm}^{2}\right)\end{array}$ & $\mathrm{PD}-1^{+}\left(\right.$cells $\left./ \mathrm{mm}^{2}\right)$ \\
\hline \multicolumn{7}{|l|}{ No. 8} \\
\hline IM & 1328 & 254 & 676 & 1355 & 628 & 764 \\
\hline CT & 109 & 13 & 7 & 1063 & 823 & 545 \\
\hline \multicolumn{7}{|l|}{ No. 4} \\
\hline IM & 1526 & 394 & 873 & 1097 & 234 & 824 \\
\hline CT & 50 & 23 & 38 & 466 & 78 & 385 \\
\hline
\end{tabular}

status can be in tumors and that molecular progression can fundamentally change the role of PD-L1 in a given cancer.

These findings raise the hypothesis that the molecular progression to small-cell bladder cancer may quite regularly involve the acquisition of a new and strong ability to defend the tumor against lymphocytic infiltration. It could be speculated that already the compact growth pattern of small-cell cancers hampers immune cell infiltration, but small-cell bladder carcinomas may also develop established molecular immune escape mechanisms including physical or chemical barriers, such as extracellular matrix remodeling or TGFbeta-1 upregulation [11, 22-24]. Whatever the mechanism may be, the acquired immune-excluded phenotype $[11,12]$ is unlikely to be due to a loss of mutation-associated neoantigens $[25,26]$ because small-cell bladder carcinomas have a higher mutational burden than urothelial carcinomas and specific mutations can hardly be lost in cancers during progression [19]. It is possible that the immune escape occurring in small-cell carcinomas is so efficient that cancer cells do not further require PD-L1 expression. Interestingly, lack of PDL1 expression has earlier been linked to "noninflamed" tumor phenotype and been reported to be common in small-cell cancers of the lung $[12,17,27]$. All these findings indicate that small-cell carcinomas of the urinary bladder may represent model tumors for immune oncology. The frequent cooccurrence of a morphologically defined inflamed cancer and its immune-excluded postprogression counterpart may be excellently suited to study the molecular mechanisms underlying downregulation of PD-L1 and the development of "immune exclusion."

The immune-excluded and immune-desert phenotypes have initially been described as noninflamed [11,12] microenvironments that might respond less favorably to immune checkpoint therapy than the inflamed phenotype [12]. However, there is accumulating evidence that the degree of lymphocytic infiltration at the IM might be more predictive for outcome than that in the CT. For example, higher lymphocytic infiltration at the IM than in the CT has been described particularly in tumor entities that often respond to anticheckpoint therapy [4, 28-32], such as non-small-cell lung cancer, squamous cell carcinoma of the head and neck, or renal cell carcinoma [33, 34]. Moreover, the amount of $\mathrm{CD}^{+}$cytotoxic $\mathrm{T}$ lymphocytes within the IM was the best predictive parameter for clinical response to checkpoint therapy in a study analyzing metastatic melanoma [9]. Our study demonstrates that most urothelial carcinomas have more
$\mathrm{CD}^{+}$cytotoxic T cells at the IM than in the CT and that this particularly applies to small-cell bladder cancers. The typically high number of $\mathrm{CD}^{+}$at the IM of small-cell bladder cancers may explain a recent report of a patient with smallcell carcinoma of the bladder responding well to pembrolizumab [5].

In conclusion, the result of our study highlights immune exclusion as a key feature of small-cell bladder cancer. Progression of small-cell bladder cancer from urothelial cancer represents a model case of a near complete change in the immune environment going along with morphological-and most likely also-genomic dedifferentiation of bladder cancer. Small-cell bladder cancer may benefit from treatment strategies that are specifically designed to overcome immune exclusion.

\section{Data Availability}

The data used to support the findings of this study are available from the corresponding author upon request.

\section{Conflicts of Interest}

The authors declare that they have no conflict of interest.

\section{Supplementary Materials}

Figure S1: CD3-, CD8-, and PD-1-positive cell densities of 12 patients with small-cell carcinoma of the bladder at the invasive margin (IM) and the center of the tumor (CT) (P1-P12). (Supplementary Materials)

\section{References}

[1] N. W. Choong, J. F. Quevedo, and J. S. Kaur, "Small cell carcinoma of the urinary bladder. The Mayo Clinic experience," Cancer, vol. 103, no. 6, pp. 1172-1178, 2005.

[2] N. Ismaili, "A rare bladder cancer-small cell carcinoma: review and update," Orphanet Journal of Rare Diseases, vol. 6, no. 1, p. 75, 2011.

[3] L. Cheng, C. X. Pan, X. J. Yang et al., "Small cell carcinoma of the urinary bladder: a clinicopathologic analysis of 64 patients," Cancer, vol. 101, no. 5, pp. 957-962, 2004.

[4] F. S. Hsu, C. H. Su, and K. H. Huang, "A comprehensive review of US FDA-approved immune checkpoint inhibitors in urothelial carcinoma," Journal of Immunology Research, vol. 2017, Article ID 6940546, 9 pages, 2017. 
[5] L. Wilde, S. M. Ali, C. C. Solomides, J. S. Ross, E. Trabulsi, and J. Hoffman-Censits, "Response to pembrolizumab in a patient with chemotherapy refractory bladder cancer with small cell variant histology: a case report and review of the literature," Clinical Genitourinary Cancer, vol. 15, no. 3, pp. e521-e524, 2017.

[6] G. V. Masucci, A. Cesano, R. Hawtin et al., "Validation of biomarkers to predict response to immunotherapy in cancer: volume I - pre-analytical and analytical validation," Journal for ImmunoTherapy of Cancer, vol. 4, no. 1, p. 76, 2016.

[7] K. Shien, V. A. Papadimitrakopoulou, and I. I. Wistuba, "Predictive biomarkers of response to PD-1/PD-L1 immune checkpoint inhibitors in non-small cell lung cancer," Lung Cancer, vol. 99, pp. 79-87, 2016.

[8] J. Galon, A. Costes, F. Sanchez-Cabo et al., "Type, density, and location of immune cells within human colorectal tumors predict clinical outcome," Science, vol. 313, no. 5795, pp. 19601964, 2006.

[9] P. C. Tumeh, C. L. Harview, J. H. Yearley et al., "PD-1 blockade induces responses by inhibiting adaptive immune resistance," Nature, vol. 515, no. 7528, pp. 568-571, 2014.

[10] A. P. Cogdill, M. C. Andrews, and J. A. Wargo, "Hallmarks of response to immune checkpoint blockade," British Journal of Cancer, vol. 117, no. 1, pp. 1-7, 2017.

[11] D. S. Chen and I. Mellman, "Elements of cancer immunity and the cancer-immune set point," Nature, vol. 541, no. 7637, pp. 321-330, 2017.

[12] P. S. Hegde, V. Karanikas, and S. Evers, "The where, the when, and the how of immune monitoring for cancer immunotherapies in the era of checkpoint inhibition," Clinical Cancer Research, vol. 22, no. 8, pp. 1865-1874, 2016.

[13] J. E. Rosenberg, J. Hoffman-Censits, T. Powles et al., "Atezolizumab in patients with locally advanced and metastatic urothelial carcinoma who have progressed following treatment with platinum-based chemotherapy: a single-arm, multicentre, phase 2 trial," Lancet, vol. 387, no. 10031, pp. 1909-1920, 2016.

[14] S. Tippmann, "Programming tools: adventures with R," Nature, vol. 517, no. 7532, pp. 109-110, 2015.

[15] J. M. Kim and D. S. Chen, "Immune escape to PD-L1/PD-1 blockade: seven steps to success (or failure)," Annals of Oncology, vol. 27, no. 8, pp. 1492-1504, 2016.

[16] S. O. Olugbile, R. Bao, R. F. Sweis et al., "Molecular characterization of immune exclusion in small-cell lung cancer," Journal of Clinical Oncology, vol. 34, Supplement 15, p. 8565, 2016.

[17] J. K. Sabari, B. H. Lok, J. H. Laird, J. T. Poirier, and C. M. Rudin, "Unravelling the biology of SCLC: implications for therapy," Nature Reviews Clinical Oncology, vol. 14, no. 9, pp. 549-561, 2017.

[18] L. Terracciano, J. Richter, L. Tornillo et al., "Chromosomal imbalances in small cell carcinomas of the urinary bladder," The Journal of Pathology, vol. 189, no. 2, pp. 230-235, 1999.

[19] M. T. Chang, A. Penson, N. B. Desai et al., "Small-cell carcinomas of the bladder and lung are characterized by a convergent but distinct pathogenesis," Clinical Cancer Research, vol. 24, no. 8, pp. 1965-1973, 2018.

[20] X. Zheng, J. Zhuge, S. M. Bezerra et al., "High frequency of TERT promoter mutation in small cell carcinoma of bladder, but not in small cell carcinoma of other origins," Journal of Hematology \& Oncology, vol. 7, no. 1, p. 47, 2014.

[21] T. D. Jones, K. M. Kernek, X. J. Yang et al., "Thyroid transcription factor 1 expression in small cell carcinoma of the urinary bladder: an immunohistochemical profile of 44 cases," Human Pathology, vol. 36, no. 7, pp. 718-723, 2005.

[22] A. Helmy, O. A. Hammam, T. R. El Lithy, and M. M. El Deen Wishahi, "The role of TGF-beta-1 protein and TGF-beta-R-1 receptor in immune escape mechanism in bladder cancer," Medscape General Medicine, vol. 9, no. 4, p. 34, 2007.

[23] F. G. Perabo, S. Kamp, D. Schmidt et al., "Bladder cancer cells acquire competent mechanisms to escape Fas-mediated apoptosis and immune surveillance in the course of malignant transformation," British Journal of Cancer, vol. 84, no. 10, pp. 1330-1338, 2001.

[24] W. H. Liu, Y. Y. Chen, S. X. Zhu et al., "B7-H4 expression in bladder urothelial carcinoma and immune escape mechanisms," Oncology Letters, vol. 8, no. 6, pp. 2527-2534, 2014.

[25] L. B. Alexandrov, S. Nik-Zainal, D. C. Wedge et al., "Signatures of mutational processes in human cancer," Nature, vol. 500, no. 7463, pp. 415-421, 2013.

[26] T. N. Schumacher and R. D. Schreiber, "Neoantigens in cancer immunotherapy," Science, vol. 348, no. 6230, pp. 69-74, 2015.

[27] J. M. Taube, A. Klein, J. R. Brahmer et al., "Association of PD1, PD-1 ligands, and other features of the tumor immune microenvironment with response to anti-PD-1 therapy," Clinical Cancer Research, vol. 20, no. 19, pp. 5064-5074, 2014.

[28] J. Bellmunt, R. de Wit, D. J. Vaughn et al., "Pembrolizumab as second-line therapy for advanced urothelial carcinoma," The New England Journal of Medicine, vol. 376, no. 11, pp. 10151026, 2017.

[29] F. Massari, V. Di Nunno, M. Cubelli et al., "Immune checkpoint inhibitors for metastatic bladder cancer," Cancer Treatment Reviews, vol. 64, pp. 11-20, 2018.

[30] P. Msaouel and E. Massarelli, "Immune checkpoint therapy in head and neck cancers," Cancer Journal, vol. 22, no. 2, pp. 108116, 2016.

[31] H. I. Assi, A. O. Kamphorst, N. M. Moukalled, and S. S. Ramalingam, "Immune checkpoint inhibitors in advanced non-small cell lung cancer," Cancer, vol. 124, no. 2, pp. 248-261, 2018.

[32] K. Ross and R. J. Jones, "Immune checkpoint inhibitors in renal cell carcinoma," Clinical Science, vol. 131, no. 21, pp. 2627-2642, 2017.

[33] K. E. Steele, T. H. Tan, R. Korn et al., "Measuring multiple parameters of CD8+ tumor-infiltrating lymphocytes in human cancers by image analysis," Journal for ImmunoTherapy of Cancer, vol. 6, no. 1, p. 20, 2018.

[34] Y. A. Cho, H. J. Yoon, J. I. Lee, S. P. Hong, and S. D. Hong, "Relationship between the expressions of PD-L1 and tumorinfiltrating lymphocytes in oral squamous cell carcinoma," Oral Oncology, vol. 47, no. 12, pp. 1148-1153, 2011. 


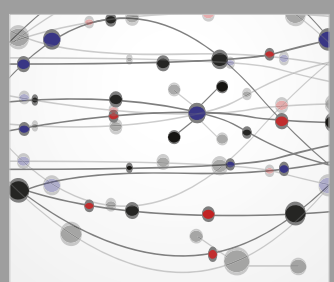

The Scientific World Journal
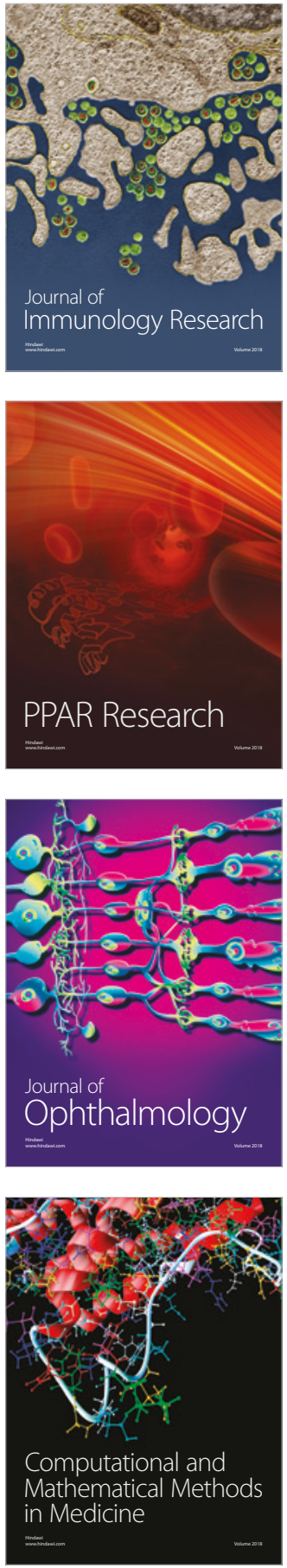

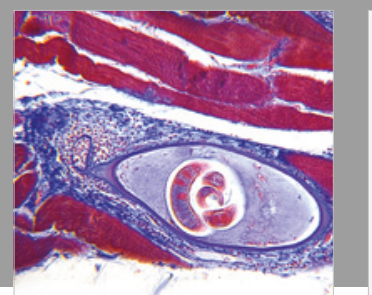

Gastroenterology Research and Practice

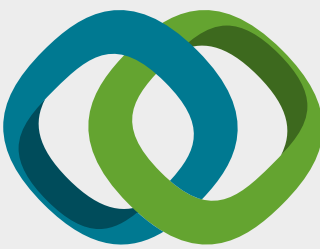

\section{Hindawi}

Submit your manuscripts at

www.hindawi.com
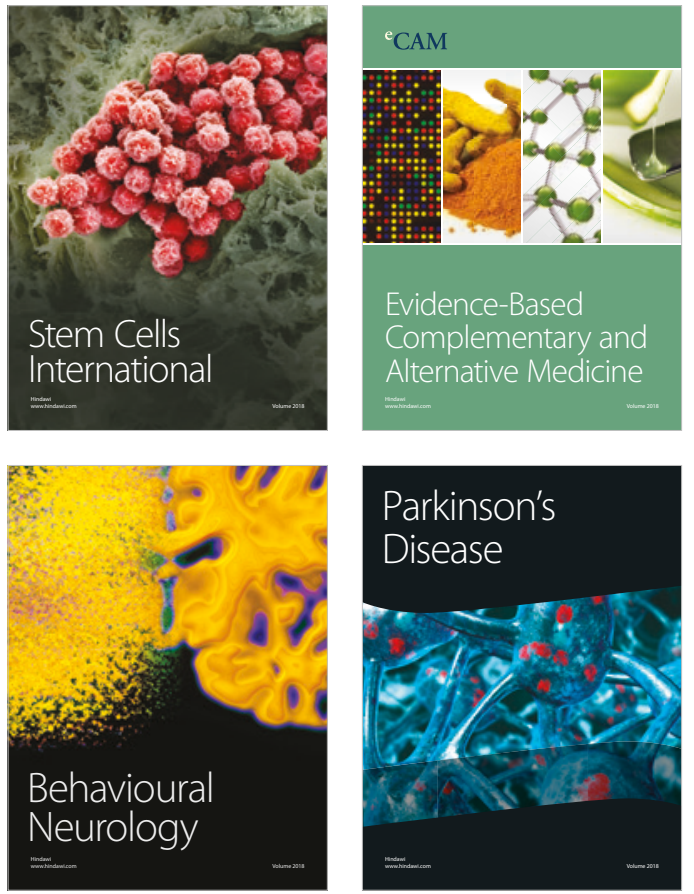

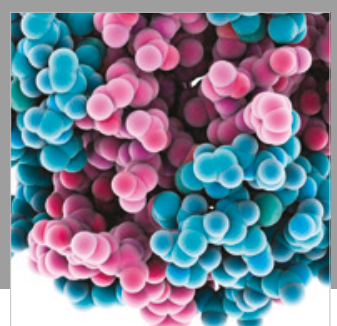

ournal of

Diabetes Research

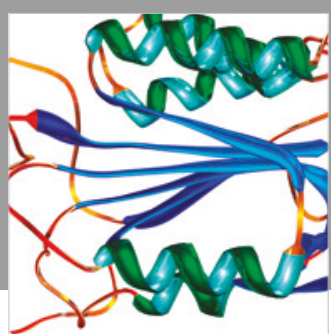

Disease Markers
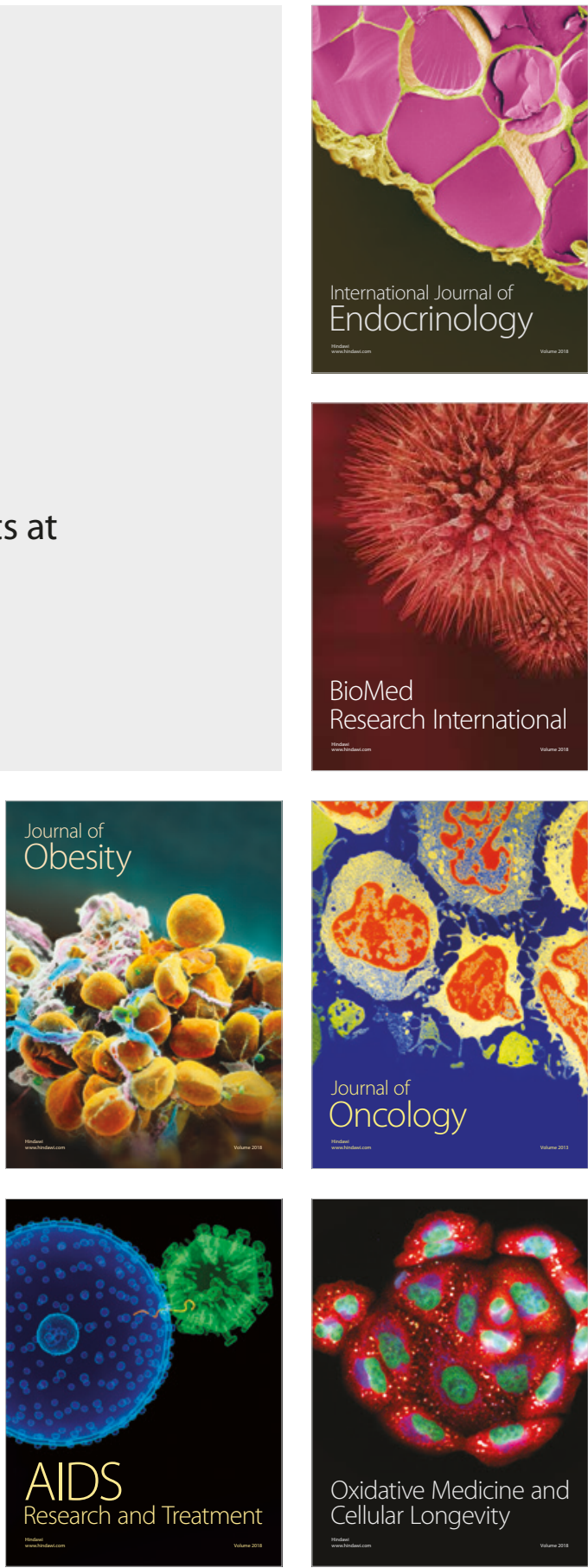